\title{
Cyst Fluid Carcinoembryonic Antigen Level Difference between Mucinous Cystic Neoplasms and Intraductal Papillary Mucinous Neoplasms
}

\author{
Ibrahim Hakkı Köker', Nurcan Ünver², Fatma Ümit Malya ${ }^{3}$, Ömer Uysal', Elmas Biberci Keskin ${ }^{1}$ and Hakan Şentürk' \\ Departments of ${ }^{1}$ Gastroenterology, ${ }^{2}$ Pathology, ${ }^{3}$ General Surgery, ${ }^{4}$ Biostatistics, Bezmialem Vakif University Medicine Faculty, Istanbul, \\ Turkey
}

Background/Aims: The role of cyst fluid carcinoembryonic antigen (CEA) level in differentiating mucinous pancreatic cystic lesions (PCLs) is controversial. We investigated the role of cyst fluid CEA in differentiating low-risk (LR)-intraductal papillary mucinous neoplasms (IPMNs) from high-risk (HR)-IPMNs and LR-mucinous cystic neoplasms (MCNs).

Methods: This was a retrospective study of 466 patients with PCLs who underwent endoscopic ultrasound-guided fine-needleaspiration over a 7-year period. On histology, low-grade dysplasia and intermediate-grade dysplasia were considered LR, whereas high-grade dysplasia and invasive carcinoma were considered HR.

Results: Data on cyst fluid CEA levels were available for 50/102 mucinous PCLs with definitive diagnoses. The median CEA (range) levels were significantly higher in HR cysts than in LR cysts $(2,624[0.5-266,510] \mathrm{ng} / \mathrm{mL}$ vs. $100[16.8-53,445] \mathrm{ng} / \mathrm{mL}, p=0.0012)$. The area under the receiver operating characteristic curve (AUROC) was 0.930 (95\% confidence interval [CI], $0.5-0.8 ; p<0.001$ ) for differentiating LR-IPMNs from LR-MCNs. The AUROC was 0.921 (95\% CI, 0.823-1.000; $p<0.001$ ) for differentiating LR-IPMNs from HR-IPMNs. Both had a CEA cutoff level of $>100 \mathrm{ng} / \mathrm{mL}$, with a negative predictive value (NPV) of $100 \%$.

Conclusions: Cyst fluid CEA levels significantly vary between LR-IPMNs, LR-MCNs, and HR-IPMNs. A CEA cutoff level of $>100 \mathrm{ng} / \mathrm{mL}$ had a 100\% NPV in differentiating LR-IPMNs from LR-MCNs and HR-IPMNs. Clin Endosc 2021;54:113-121

Key Words: Carcinoembryonic antigen; Malignancy; Pancreatic cysts

\section{INTRODUCTION}

Pancreatic cystic lesions (PCLs) are incidentally detected at a rate of $8 \%$, and they are primarily $(60 \%)$ mucinous. ${ }^{1}$ Mucinous PCLs include intraductal papillary mucinous neoplasms (IPMNs), mucinous cystic neoplasms (MCNs), intraductal oncocytic papillary neoplasms, cystic changes in ordinary duc-

\footnotetext{
Received: April 1,2020 Revised: June 1,2020

Accepted: June 22, 2020

Correspondence: Hakan Şentürk

Departments of Gastroenterology, Bezmialem Vakif University Medicine Faculty, Iskender Pasa Mh. Vatan Cad. Fatih, Istanbul 34093, Turkey

Tel: +90-532-312-8340, Fax: +90-212-453-1883, E-mail: drhakansenturk@yahoo. com

ORCID: https://orcid.org/0000-0002-2440-4478
}

cc This is an Open Access article distributed under the terms of the Creative Commons Attribution Non-Commercial License (http://creativecommons.org/ licenses/by-nc/3.0) which permits unrestricted non-commercial use, distribution, and reproduction in any medium, provided the original work is properly cited. tal adenocarcinomas, and other invasive carcinomas, such as cystic pancreatic ductal adenocarcinoma (PDAC). ${ }^{2}$ Given the malignant potential of MCNs (10\%-39\%) and IPMNs (36\%$100 \%)$, routine monitoring is mandatory. ${ }^{3}$ However, there is no single criterion or follow-up model for mucinous PCLs. We aimed to analyze the role of cyst fluid carcinoembryonic antigen (CEA) level in differentiating MCNs from IPMNs as well as low-risk (LR)- versus high-risk (HR)-IPMNs.

\section{MATERIALS AND METHODS}

The study population consisted of 466 patients with PCLs referred to our unit, who underwent endoscopic ultrasound-guided fine-needle aspiration (EUS-FNA) of cyst fluid between 2011 and 2018. Demographic data, medical history, and cross-sectional imaging results were retrieved from the 
electronic medical records. All procedures were part of standard patient care. This retrospective study was approved by the local ethics committee.

\section{Endoscopic ultrasound methods}

After providing informed consent, all patients underwent EUS examination (A121091, H121645, H121435, H121637; Pentax Medical Co., Montvale, NJ, USA, K1U047K062; Fujifilm Co., Tokyo, Japan). EUS-FNA was performed with either a 22- or 19-gauge FNA needle (Cook Medical, Bloomington, IN, USA, or Boston Scientific, Marlborough, MA, USA). Prophylactic, single-dose, intravenous antibiotics were administered before cyst puncture. All patients from whom sufficient fluid was aspirated for cytologic analysis and CEA measurement were included.

\section{Diagnostic criteria for pancreatic cystic lesions}

\section{Endoscopic ultrasound imaging}

A preliminary diagnosis was made after reviewing the demographic and clinical data together with the cyst morphology evaluated with EUS.

\section{Cytology}

Cystic fluid was analyzed for mucin and cell morphology. All cytologic analyses were performed or reviewed by an expert pancreatic cytopathologist, and categorized as diagnostic or nondiagnostic. Diagnostic samples had a mucinous epithelium, whereas nondiagnostic samples contained either a nonmucinous epithelium or no epithelial cells. A mucinous epithelium was graded according to epithelial atypia as LR, lowgrade dysplasia (LGD) or intermediate-grade dysplasia (IGD), or HR, high-grade dysplasia (HGD) or invasive carcinoma. ${ }^{5}$

\section{Histology}

Histologic diagnoses were made using surgical specimens. The resection cohort included cases with histologically confirmed MCNs and IPMNs. All histologic analyses were performed or reviewed by the study pathologist. Ovarian-type stroma was required for a diagnosis of $\mathrm{MCN}$. The resected cystic lesions were categorized according to the World Health Organization classification system. ${ }^{6}$ MCNs and IPMNs were classified as LR (LGD or IGD in resection material) or HR (HGD or invasive carcinoma in resection material).

\footnotetext{
Analysis of cyst fluid carcinoembryonic antigen

Cyst fluid CEA levels were measured using a carbonylmetallo-immunoassay kit (ARCHITECT i2000SR; Abbott Core Laboratory, Abbott Park, IL, USA). A minimum of $0.3 \mathrm{~mL}$ was required for each analysis.
}

\section{Data collection}

All data were retrospectively collected and recorded in a database. The study group consisted of patients with a final diagnosis based on cytology or specimen histology with a specific diagnosis. Separate receiver operating characteristic (ROC) curves were plotted for cyst fluid CEA levels to differentiate LR-IPMNs from LR-MCNs and HR-IPMNs. The area under the ROC curve (AUROC) was calculated. Sensitivity, specificity, positive predictive value (PPV), and negative predictive value (NPV) were calculated for cyst fluid CEA cutoff levels to maximize the ratio of correct diagnoses of mucinous-subtype PCLs.

\section{Statistical analysis}

All statistical analyses were performed using SPSS Statistics software version 25 (IBM Co., Armonk, NY, USA). The Kolmogorov-Smirnov and Shapiro-Wilk tests showed a nonnormal data distribution. Descriptive statistics are presented using medians and ranges for nonnormally distributed and ordinal variables. A comparison of cyst fluid CEA was performed among the four cyst types, LR-MCNs, LR-IPMNs, HR-IPMNs, and cystic PDACs, using the nonparametric Kruskal-Wallis test. When the results of the Kruskal-Wallis test were statistically significant, the four groups were compared in pairs in a total of six comparisons using the Mann-Whitney $U$ test. We used Bonferroni's adjustment in two groups. The first group included three subgroups (MCNs, IPMNs, and cystic PDACs), and the second group included four subgroups (MCNs, LRIPMNs, HR-IPMNs, and cystic PDACs). Owing to multiple pairwise comparisons, $p$-values of $<0.017$ and $<0.008$, respectively, were required for significance. Data of cyst fluid CEA levels were used to plot two ROC curves to differentiate LRIPMNs from LR-MCNs and HR-IPMNs, and the AUROC was calculated. The AUROC was defined as low $(0.5$ to $<0.7)$, moderate $(0.7$ to $<0.9)$, or high $(\geq 0.9)$. MedCalc Statistical Software version 19.2.5 (MedCalc Software Ltd., Ostend, Belgium; https://www.medcalc.org; 2020) was used to determine the cyst fluid CEA cutoff levels for the accurate diagnostic differentiation of LR-IPMNs from LR-MCNs and HR-IPMNs. A $p$-value of $<0.05$ was considered significant.

\section{RESULTS}

A total of 466 patients with PCLs were evaluated with EUSFNA over 7 years. Among these, cyst fluid cytology was examined in $340(72.9 \%)$ patients and cyst fluid CEA measurement was available in 255 (54.7\%) patients. Diagnosis was based on definitive cytology and/or surgical specimens in 102 muci- 


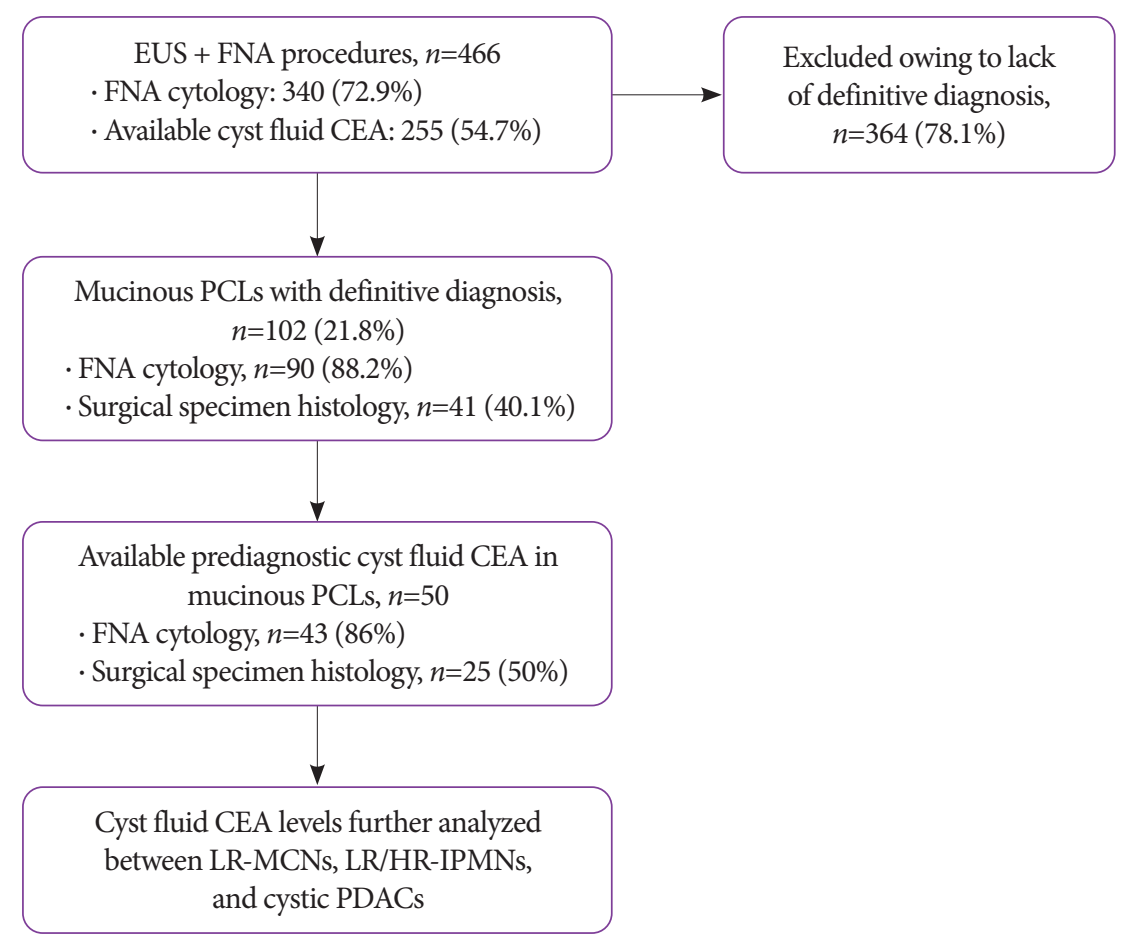

Fig. 1. Flowchart of the patients recruited to the study. CEA, carcinoembryonic antigen; EUS, endoscopic ultrasound; FNA, fine-needle aspiration; HR, high risk; IPMN, intraductal papillary mucinous neoplasm; LR, low risk; MCN, mucinous cystic neoplasm; PCL, pancreatic cystic lesion; PDAC, pancreatic ductal adenocarcinoma.

Table 1. Baseline Characteristics of All Mucinous Pancreatic Cystic Lesions Diagnosed Using Cytopathology

\begin{tabular}{|c|c|}
\hline & Mucinous PCLs $(n=102)$ \\
\hline Cytopathologic diagnosis (total) & 102 \\
\hline Gender, female ${ }^{a)}$ & $52(51.5)$ \\
\hline Age, mean \pm SD $(y r)$ & $61.9 \pm 13.3$ \\
\hline Cyst size, mm, median (min-max) & $30(10-90)$ \\
\hline Cyst type ${ }^{a)}$ & $\begin{array}{c}\text { IPMN: } 35(34.3) \\
\text { Cystic PDAC: } 27(26.5) \\
\text { IPMN PDAC: } 24(23.5) \\
\text { MCN: } 16(15.7)\end{array}$ \\
\hline $\begin{array}{l}\text { Cyst location }^{\text {a) }} \\
\text { Head/uncinate } \\
\text { Corpus } \\
\text { Tail } \\
\text { Several }\end{array}$ & $\begin{array}{c}51(50) \\
34(33.3) \\
15(14.7) \\
2(0.2)\end{array}$ \\
\hline Patients evaluated using EUS-FNA ${ }^{\text {a) }}$ & $90(88.2)$ \\
\hline $\begin{array}{l}\text { Patients who underwent surgical } \\
\text { resection }{ }^{\text {a) }}\end{array}$ & $41(40.1)$ \\
\hline
\end{tabular}

EUS-FNA, endoscopic ultrasound-guided fine-needle aspiration; IPMN, intraductal papillary mucinous neoplasm; MCN, mucinous cystic neoplasm; PCL, pancreatic cystic lesion; PDAC, pancreatic ductal adenocarcinoma; SD, standard deviation.

${ }^{\text {a) }}$ Values are represented as $n(\%)$. nous PCLs. Among those 102, 50 had available cyst fluid CEA results (Fig. 1). Table 1 shows the demographic data of the patients.

\section{Cyst fluid carcinoembryonic antigen analysis}

Table 2 summarizes the comparative analysis of cyst fluid CEA levels among the different mucinous cyst types. All MCNs (eight LGDs and one IGD) with preoperative cyst fluid CEA results were selected from the surgical specimen series, whereas the remaining cases were diagnosed using cytology or resection material.

The cyst fluid CEA levels in LR-MCNs $(p<0.001)$ and HRIPMNs $(p<0.001)$ were significantly higher than those in LRIPMNs. The cyst fluid CEA level of cystic-PDACs was also higher than that of LR-IPMNs $(p=0.02)$. However, the significance disappeared after Bonferroni's correction. Fig. 2. shows the distribution of cyst fluid CEA levels among the prespecified cyst types.

The decision to resect a lesion was based on the PCL guidelines in effect from 2011 to $2016 .{ }^{7.8}$ However, cases between 2016 and 2018 were more conservatively managed because of accumulating evidence. Therefore, no LR-IPMNs were resected during the last 2 years of the study. Additionally, resection of most HR-IPMNs (6/8) occurred between 2015 and 2018. 
Table 2. Cyst Fluid Carcinoembryonic Antigen Levels in Mucinous Pancreatic Cystic Lesions, Mucinous Pancreatic Cystic Lesion Subcohorts, and Resected Pancreatic Cystic Lesions

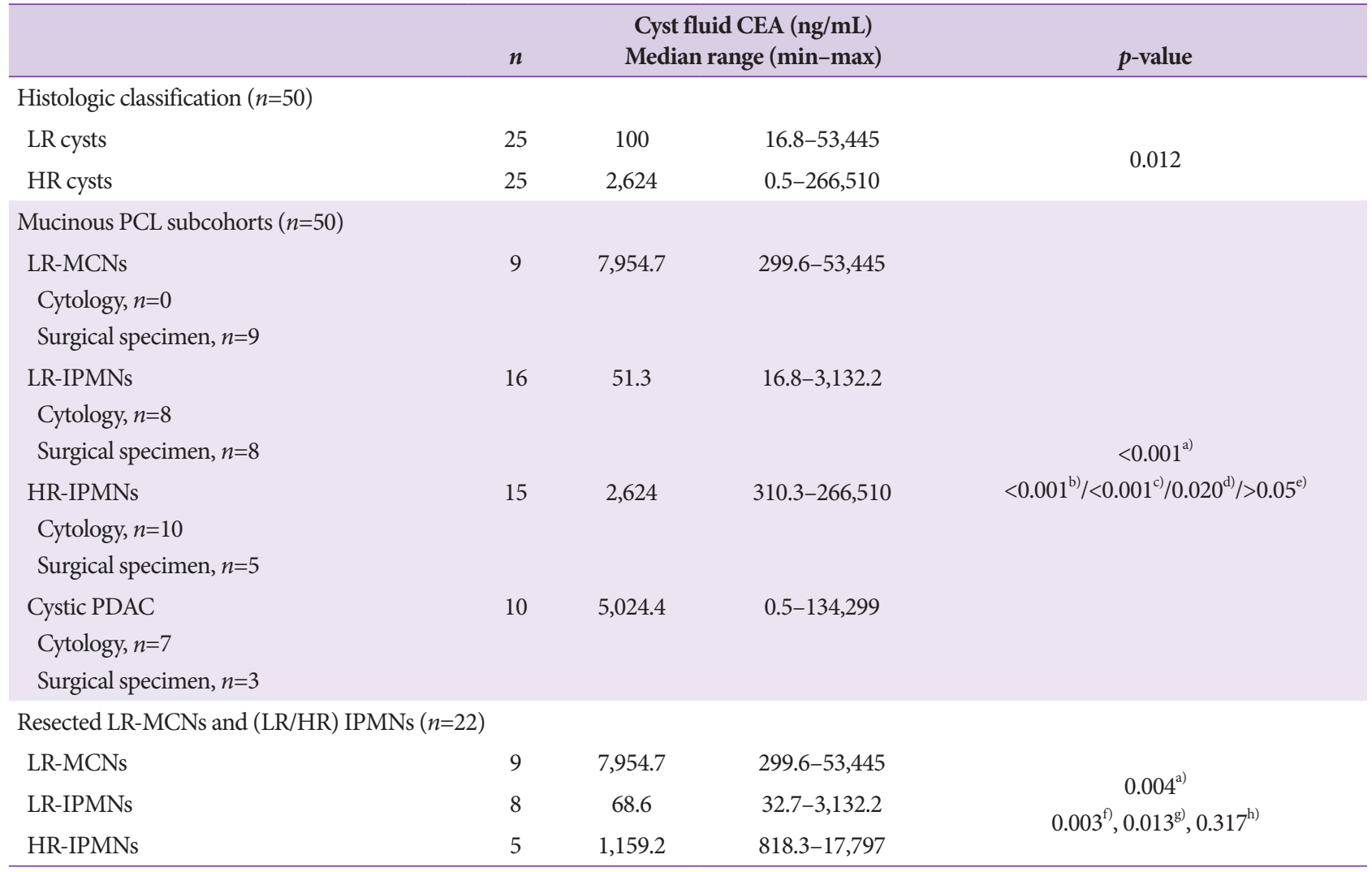

CEA, carcinoembryonic antigen; HR, high risk; IPMN, intraductal papillary mucinous neoplasm; LR, low risk; MCN, mucinous cystic neoplasm; PCL, pancreatic cystic lesion; PDAC, pancreatic ductal adenocarcinoma.

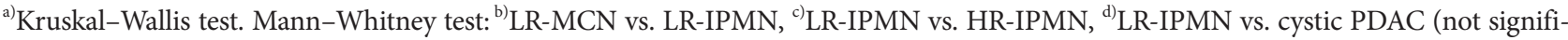

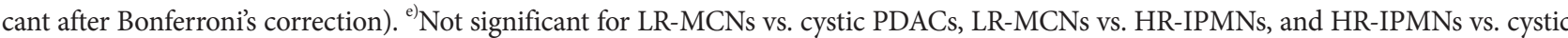
PDACs. ${ }^{\text {f) }}$ Surgical specimen LR-MCN vs. LR-IPMN. ${ }^{\text {g) }}$ Surgical specimen LR-IPMN vs. HR-IPMN (significant after Bonferroni’s correction). ${ }^{\text {h) }}$ Surgical specimen LR-MCNs vs. HR-IPMNs.

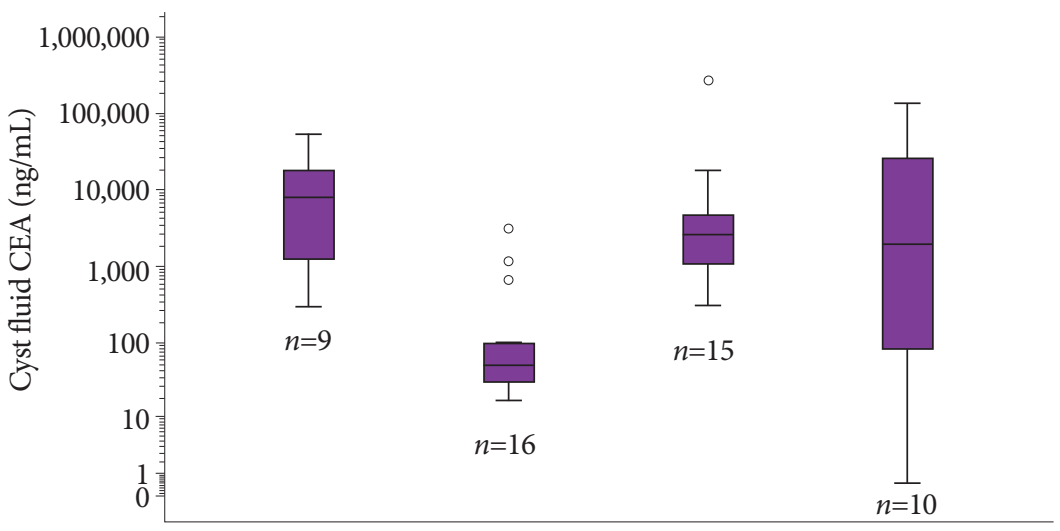

Low risk MCN Low risk IPMN High risk IPMN Cystic PDAC

Histopathologically confirmed mucinous cysts

Fig. 2. The -axis represents a logarithmic scale $(\mathrm{ng} / \mathrm{mL})$ for carcinoembryonic antigen (CEA). Median values are presented as the center lines within every box. The width of each box represents the interquartile range. The whiskers show the minimum and maximum values. Outliers are shown above the boxes. IPMN, intraductal papillary mucinous neoplasm; MCN, mucinous cystic neoplasm; PDAC, pancreatic ductal adenocarcinoma. 
Among the 16 patients with a final diagnosis of LR-IPMN (Table 2), 8 underwent surgery and had a histopathologic diagnosis. In two of the eight patients, the preoperative cyst fluid CEA level was $>100 \mathrm{ng} / \mathrm{mL}$ (664.4 and 3,132.2 ng/mL, respectively), whereas in the remaining six patients, the cyst fluid CEA level was below the cutoff value of $\leq 100 \mathrm{ng} / \mathrm{mL}$ (32.7, $33.1,40.3,59.5,77.8$, and $100 \mathrm{ng} / \mathrm{mL}$ ) (Table 2). However, the other eight patients in the LR-IPMN group were diagnosed on the basis of cytology and supporting evidence, such as cyst size, mural nodule absence, main pancreatic duct dilatation, cyst fluid CEA level, and cross-sectional imaging findings. Seven patients had cyst fluid CEA levels below the cutoff value $(16.8,19.8,22.2,27.5,43.1,79$, and $100 \mathrm{ng} / \mathrm{mL})$. Five patients had at least 1 year of follow-up without evidence of malignant transformation. The other two patients were aged 78 and 80 years, free of symptoms, and diagnosed in the last year of the study. They were clinically followed up without cross-sectional imaging and had no change in their clinical condition. The only patient in the LR-IPMN group with an elevated prediagnostic cyst fluid CEA level $(1,167 \mathrm{ng} / \mathrm{mL})$ has been followed up for 4 years with no change in cross-sectional imaging findings. However, all HR-IPMNs with surgical specimen histopathology had elevated preoperative cyst fluid CEA levels $(818.3,1,000$, 1,159.2, 3311, and 17,797 ng/mL).

We determined the optimal cutoff level of cyst fluid CEA for differentiating LR-IPMNs from LR-MCNs and HR-IPMNs by using the ROC curve. The AUROC values were 0.93 (95\% confidence interval $[\mathrm{CI}], 0.5-0.8 ; p<0.001)$ and $0.92(95 \%$

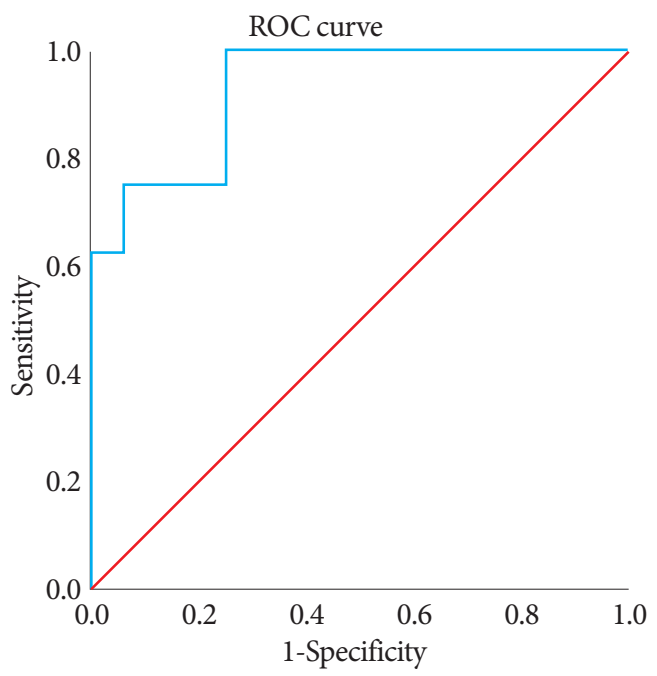

Fig. 3. Receiver operating characteristic $(\mathrm{ROC})$ curve analysis to differentiate low-risk mucinous cystic neoplasms from low-risk intraductal papillary mucinous neoplasms. A cyst fluid carcinoembryonic antigen cutoff level of $>100$ $\mathrm{ng} / \mathrm{mL}$ resulted in an area under the ROC of 0.93 (95\% confidence interval, 0.5-0.8).
CI, $0.82-1.0 ; p<0.001)$ for differentiating LR-IPMNs from LR-MCNs (Fig. 3) and HR-IPMNs (Fig. 4), respectively. The optimal cutoff level for differentiating LR-IPMNs from LRMCNs and HR-IPMNs was found to be $>100 \mathrm{ng} / \mathrm{mL}$ for both ROC curves. The sensitivity of the cyst fluid CEA cutoff level in differentiating LR-IPMNs from LR-MCNs and HR-IPMNs was $100 \%$ and $100 \%$, with a specificity of $75 \%$ and $75 \%$, PPV of $66.7 \%$ and $78.9 \%$, and NPV of $100 \%$ and $100 \%$, respectively.

\section{DISCUSSION}

In this retrospective analysis of cyst fluid CEA level to differentiate among the mucinous subtypes of PCLs, we examined cyst fluid CEA levels in cytologically or pathologically diagnosed LR-MCNs, LR/HR-IPMNs, and cystic PDACs. Among the histologically diagnosed mucinous cysts, HR cysts had significantly higher cyst fluid CEA levels than LR cysts $(p=0.012)$. The elevated cyst fluid CEA levels in LR cysts originated from MCNs (Table 2). In subcohort analyses of the 50 mucinous PCLs, cyst fluid CEA levels were significantly higher in LRMCNs $(p<0.001)$ and HR-IPMNs $(p<0.001)$ than in LRIPMNs. However, there was no significant difference in cyst fluid CEA levels between LR-MCNs and HR-IPMNs ( $p>0.05)$. Further, in the subgroup analyses of the 22 patients with surgical specimens, LR-MCNs $(p=0.003)$ and HR-IPMNs ( $p=0.013)$ had higher cyst fluid CEA levels than LR-IPMNs, whereas LR-MCNs and HR-IPMNs did not have significantly

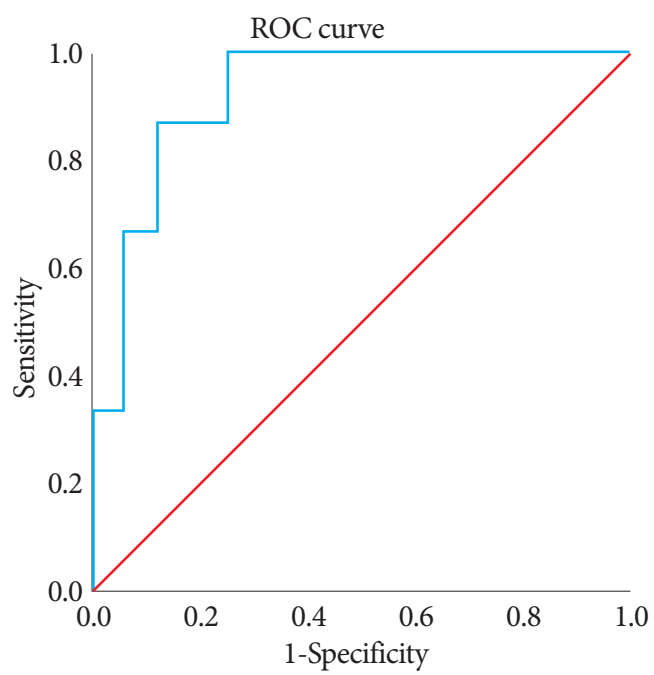

Fig. 4. Receiver operating characteristic (ROC) curve analysis to differentiate high-risk from low-risk intraductal papillary mucinous neoplasms. A cyst fluid carcinoembryonic antigen cutoff level of $>100 \mathrm{ng} / \mathrm{mL}$ resulted in an area under the ROC of 0.92 (95\% confidence interval, 0.82-1.0). 
Table 3. Previous Studies Investigating the Role of Cyst Fluid Carcinoembryonic Antigen in Predicting Mucinous Cysts and Dysplasia Grade

\begin{tabular}{|c|c|c|c|c|c|c|c|}
\hline Study & $\begin{array}{l}\text { Study } \\
\text { design }\end{array}$ & $n$ & Surgical pathology & $\begin{array}{l}\text { FNA/ } \\
\text { SS/PJ }\end{array}$ & $\begin{array}{l}\text { CEA } \\
\text { cutoff, } \\
\text { ng/mL }\end{array}$ & $\begin{array}{l}\text { Sensitivity, } \\
\text { specificity, } \\
\text { PPV, NPV }\end{array}$ & Conclusion about CEA \\
\hline $\begin{array}{l}\text { Kawai et al. } \\
(2004)^{25}\end{array}$ & Case series & 27 & HR-IPMNs & PJ & 110 & $\begin{array}{l}\text { 78.0, 91.0, } \\
\text { N/A, N/A }\end{array}$ & $\begin{array}{l}\text { Differentiate benign from malig- } \\
\text { nant cysts }\end{array}$ \\
\hline $\begin{array}{l}\text { Brugge et al. } \\
(2004)^{16}\end{array}$ & $\begin{array}{r}\text { Multicenter } \\
\text { case series }\end{array}$ & 68 & $\begin{array}{c}52 \text { (24 HR) MCNs and } \\
16 \text { (2 HR) IPMNs }\end{array}$ & FNA & 192 & $\begin{array}{l}73.0,84.0 \\
\text { N/A, N/A }\end{array}$ & $\begin{array}{l}\text { Differentiate mucinous from non- } \\
\text { mucinous cysts }\end{array}$ \\
\hline $\begin{array}{l}\text { van der Waaij } \\
\text { et al. }(2005)^{17}\end{array}$ & $\begin{array}{l}\text { Pooled anal- } \\
\text { ysis }\end{array}$ & 450 & MCA, MCAC, PC, SCA & FNA & $>800$ & $\begin{array}{l}48.0,98.0 \\
94.0,75.0\end{array}$ & $\begin{array}{l}\text { May help in differentiating benign } \\
\text { from premalignant or malignant } \\
\text { PCLs }\end{array}$ \\
\hline $\begin{array}{l}\text { Maire et al. } \\
(2008)^{26}\end{array}$ & Case series & 41 & IPMNs & FNA & $>200$ & $\begin{array}{l}90.0,71.0 \\
50.0,96.0\end{array}$ & $\begin{array}{l}\text { Differentiate benign from malig- } \\
\text { nant cysts }\end{array}$ \\
\hline $\begin{array}{l}\text { Correa-Gallego } \\
\text { et al. }(2009)^{28}\end{array}$ & Case series & 72 & IPMNs: 55 LR, 17 HR cysts & FNA & N/A & N/A & $\begin{array}{l}\text { Cannot differentiate benign from } \\
\text { malignant cysts }\end{array}$ \\
\hline $\begin{array}{l}\text { Nagula et al. } \\
(2010)^{18}\end{array}$ & Case series & 97 & $\begin{array}{l}\text { MCN (12 LR, } 2 \text { HR), IPMN (42 } \\
\text { LR, } 10 \text { HR), SCA, NET, others }\end{array}$ & FNA & $>192$ & $\begin{array}{l}73.0,65.0 \\
76.0,53.0\end{array}$ & $\begin{array}{l}\text { Useful in identification of mucinous } \\
\text { cysts }\end{array}$ \\
\hline $\begin{array}{l}\text { Park et al. } \\
(2011)^{19}\end{array}$ & Case series & 126 & $\begin{array}{l}\text { Various cysts (104 resection, } \\
22 \text { biopsy or cytology); MCN, } \\
\text { IPMN, mucin cancers, includ- } \\
\text { ing PDAC, SCA, PC, PNET, } \\
\text { and others }\end{array}$ & FNA & $\geq 200$ & $\begin{array}{l}60.0,93.0 \\
\text { N/A, N/A }\end{array}$ & $\begin{array}{l}\text { CEA is not diagnostic for differ- } \\
\text { entiating benign from malignant } \\
\text { mucinous cysts }\end{array}$ \\
\hline $\begin{array}{l}\text { Cizginer et al. } \\
(2011)^{20}\end{array}$ & Case series & 198 & $\begin{array}{l}\text { MCNs and IPMNs with hetero- } \\
\text { geneous histologic grade; } 166 \\
\text { (resection), } 26 \text { (biopsy), and } 4 \\
\text { malignant (cytology) }\end{array}$ & FNA & 109.9 & $\begin{array}{l}80.9,97.7 \\
\text { N/A, N/A }\end{array}$ & $\begin{array}{l}\text { Does not distinguish benign from } \\
\text { malignant cysts }\end{array}$ \\
\hline $\begin{array}{l}\text { Al-Rashdan et } \\
\text { al. }(2011)^{21}\end{array}$ & Case series & 25 & $\begin{array}{c}9 \text { MCNs, } 11 \text { (1 ICA, } 5 \text { HGD) } \\
\text { BD-IPMNs, } 5 \text { (1 ICA) MD- } \\
\text { IPMNs }\end{array}$ & FNA & N/A & N/A & $\begin{array}{l}\text { Of limited value in the differential } \\
\text { diagnosis of mucinous pancreas } \\
\text { cysts }\end{array}$ \\
\hline $\begin{array}{l}\text { Kucera et al. } \\
(2012)^{29}\end{array}$ & Case series & 47 & IPMN & FNA & $>200$ & $\begin{array}{r}52.4,42.3 \\
42.3,52.4\end{array}$ & $\begin{array}{l}\text { CEA is a poor predictor of malig- } \\
\text { nant IPMN }\end{array}$ \\
\hline $\begin{array}{l}\text { Ngamrueng- } \\
\text { phong et al. } \\
(2013)^{22}\end{array}$ & $\begin{array}{l}\text { Meta-analy- } \\
\text { sis }\end{array}$ & 504 & $\begin{array}{c}\text { MCN, IPMN, PC, SCN, MCA, } \\
\text { MCAC }\end{array}$ & FNA & $\begin{array}{r}109.9- \\
6,000\end{array}$ & $\mathrm{~N} / \mathrm{A}$ & $\begin{array}{l}\text { Poor ability to distinguish benign } \\
\text { from malignant cysts }\end{array}$ \\
\hline $\begin{array}{l}\text { Nagashio et al. } \\
(2014)^{23}\end{array}$ & Case series & 68 & $\begin{array}{c}\operatorname{IPMN}(18), \mathrm{MCN}(21), \mathrm{SCN} \\
\text { (15), PC (10), EC (2), LC (1), } \\
\text { SPN (1) }\end{array}$ & $\begin{array}{l}\text { FNA/ } \\
\text { SS }\end{array}$ & $>67.3$ & $\begin{array}{l}89.2,77.8 \\
\text { N/A, N/A }\end{array}$ & $\begin{array}{l}\text { Helpful in differentiating mucinous } \\
\text { from nonmucinous lesions but not } \\
\text { malignant from benign }\end{array}$ \\
\hline $\begin{array}{l}\text { Gaddam et al. } \\
(2015)^{24}\end{array}$ & $\begin{array}{l}\text { Multicenter } \\
\text { case series }\end{array}$ & 226 & $\begin{array}{l}150 \text { mucinous (43 with PDAC) } \\
\text { / } 76 \text { nonmucinous ( } 29 \mathrm{SCN} \text { ) }\end{array}$ & FNA & 105 & $\begin{array}{l}70.0,63.0 \\
\text { N/A, N/A }\end{array}$ & $\begin{array}{l}\text { Suboptimal in differentiating muci- } \\
\text { nous from nonmucinous PCLs }\end{array}$ \\
\hline $\begin{array}{l}\text { Oppong et al. } \\
(2015)^{27}\end{array}$ & Case series & 119 & $\begin{array}{c}79 \text { mucinous, } 40 \text { nonmucinous } \\
\text { cysts }\end{array}$ & FNA & $>7$ & $\begin{array}{c}94,75 \\
\text { N/A, N/A }\end{array}$ & $\begin{array}{l}\text { Distinguishes mucinous from non- } \\
\text { mucinous and HR from LR cysts }\end{array}$ \\
\hline $\begin{array}{l}\text { Scourtas et al. } \\
(2017)^{30}\end{array}$ & Case series & 54 & $\mathrm{MCN}$ & FNA & N/A & $\mathrm{N} / \mathrm{A}$ & $\begin{array}{l}\text { No conclusion about CEA but high- } \\
\text { er cyst fluid CEA levels detected in } \\
\text { HR cysts }\end{array}$ \\
\hline $\begin{array}{l}\text { Oh et al. } \\
(2017)^{12}\end{array}$ & Case series & 48 & $\begin{array}{c}16 \text { MCNs, } 13 \text { IPMNs, } 19 \text { non- } \\
\text { mucinous cysts }\end{array}$ & FNA & 48.6 & $\begin{array}{l}72.4,94.7 \\
\text { N/A, N/A }\end{array}$ & $\begin{array}{l}\text { Combination of cyst fluid CEA, } \\
\text { cytology, and viscosity increased } \\
\text { the overall diagnostic accuracy of } \\
\text { mucinous cysts }\end{array}$ \\
\hline
\end{tabular}


Table 3. Continued

\begin{tabular}{|c|c|c|c|c|c|c|c|}
\hline Study & $\begin{array}{l}\text { Study } \\
\text { design }\end{array}$ & $n$ & Surgical pathology & $\begin{array}{l}\text { FNA/ } \\
\text { SS/PJ }\end{array}$ & $\begin{array}{l}\text { CEA } \\
\text { cutoff, } \\
\text { ng/mL }\end{array}$ & $\begin{array}{l}\text { Sensitivity, } \\
\text { specificity, } \\
\text { PPV, NPV }\end{array}$ & Conclusion about CEA \\
\hline $\begin{array}{l}\text { Hirono et al. } \\
(2017)^{32}\end{array}$ & Case series & 140 & $51 \mathrm{MD}, 89$ mixed IPMNs & PJ & $\begin{array}{l}150 \text { for } \\
\text { mixed, } \\
300 \text { for } \\
M D\end{array}$ & $\begin{array}{c}73.3,69.5 \\
55.0,83.7 \\
79.0,87.5 \\
79.0,87.5\end{array}$ & $\begin{array}{l}\text { May predict ICA in MD and mixed } \\
\text { IPMNs }\end{array}$ \\
\hline $\begin{array}{l}\text { Hayakawa et al. } \\
(2019)^{31}\end{array}$ & Case series & 63 & IPMN & PJ & 97 & $\begin{array}{l}45.0,100.0 \\
65.0,100.0\end{array}$ & $\begin{array}{l}\text { Useful in diagnosis of HR-IPMNs } \\
\text { and in predicting future malignant } \\
\text { transformation }\end{array}$ \\
\hline
\end{tabular}

BD, branch duct; CEA, carcinoembryonic antigen; EC, epidermoid cyst; FNA, fine-needle aspiration; HGD, high-grade dysplasia; HR, high risk; ICA, invasive carcinoma; IPMN, intraductal papillary mucinous neoplasm; LC, lymphoepithelial cyst; LR, low risk; MCA, mucinous cystadenoma; MCAC, mucinous cystadenocarcinoma; MCN, mucinous cystic neoplasm; MD, main duct; N/A, not available; NET, neuroendocrine tumor; NPV, negative predictive value; PC, pseudocyst; PCL, pancreatic cystic lesion; PDAC, pancreatic ductal adenocarcinoma; PJ, pancreatic juice; PNET, pancreatic neuroendocrine tumor; PPV, positive predictive value; SCA, serous cyst adenoma; SCN, serous cystic neoplasia; SPN, solid pseudopapillary neoplasm; SS, surgical specimen.

different cyst fluid CEA levels ( $p=0.317$ ) (Table 2).

Cross-sectional imaging, EUS with or without FNA, needle-based confocal laser endomicroscopy, and EUS-guided microforceps biopsy are the most frequently used methods for the diagnosis and surveillance of PCLs. ${ }^{9-12}$ Japanese, European, and American guidelines for the management of pancreatic cysts do not include cyst fluid CEA level as a parameter for differentiating benign from malignant cysts. ${ }^{13-15}$ Table 3 summarizes previous studies that investigated the role of cyst fluid CEA in predicting mucinous cysts and dysplasia. However, a considerable degree of heterogeneity exists among the studies with respect to mucinous cyst groups, such as including MCN and IPMN data, with various dysplasia grades, in the same cohort. ${ }^{16-24}$ The 2018 European PCL guidelines stated that differentiating MCNs from IPMNs according to cyst fluid CEA level or cytology was not possible, ${ }^{13}$ although this statement was not supported with evidence.

Kawai et al., ${ }^{25}$ Maire et al., ${ }^{26}$ and Oppong et al. ${ }^{27}$ observed significantly different cyst fluid CEA levels between LR- and HR-IPMNs. However, Correa-Gallego et al. ${ }^{28}$ reported inconsistent results about the ability of cyst fluid CEA levels to distinguish between LR and HR mucinous cysts in a large series of resected IPMNs. In another study by Kucera et al., ${ }^{29}$ a significant correlation was reported between cyst fluid CEA level and progressive dysplasia; however, they reported that once invasive carcinoma developed, the cyst fluid CEA levels markedly declined. In addition, a meta-analysis with significant heterogeneity concluded that cyst fluid CEA level was a weak indicator of malignancy. ${ }^{22}$ Our data do not support this observation. In this study, HR-IPMNs had significantly higher cyst fluid CEA levels than LR-IPMNs $(p<0.001)$ (Fig. 2, Table 2 ). A considerable overlap in the range of cyst fluid CEA levels among LR and HR cysts has also been reported. ${ }^{30}$ These findings prompted us to determine two cutoff levels for cyst fluid CEA for differentiating LR-IPMNs from HR-IPMNs and LRMCNs.

The diagnostic ability of a cyst fluid CEA cutoff level to differentiate LR-IPMNs from LR-MCNs and HR-IPMNs had a sensitivity of $100 \%$ and $100 \%$, specificity of $75 \%$ and $75 \%$, PPV of $66.7 \%$ and $78.9 \%$, and NPV of $100 \%$ and $100 \%$, respectively. A large variation in the sensitivity and specificity of cyst fluid CEA levels with various cutoff values was observed in earlier studies (Table 3). In the present study, cyst fluid CEA level $>100 \mathrm{ng} / \mathrm{mL}$ was determined to be the cutoff value for all patients with histopathologically confirmed HR-IPMN. We determined the sensitivity of this cutoff value to be $100 \%$. None of the previous studies that determined a cutoff value reported a sensitivity of $100 \%$. However, we believe that this high sensitivity was due to the separation of HR-IPMNs from cystic PDACs. As shown in Table 2, cyst fluid CEA levels in cystic PDACs ranged from 0.5 to $134,299 \mathrm{ng} / \mathrm{mL}$.

In previous studies, Maire et al. ${ }^{26}$ and Hayakawa et al. ${ }^{31}$ also found a high NPV (97\% and 100\%, respectively) for cyst fluid CEA cutoff levels of 200 and $97 \mathrm{ng} / \mathrm{mL}$, respectively. These values were useful in differentiating benign from malignant lesions, as well as in predicting future malignant transformation. Our data support their findings and conclusions. We also calculated a cutoff value ( $>100 \mathrm{ng} / \mathrm{mL}$ ) through ROC curve 
analysis, which has a 100\% NPV for differentiating benign from malignant lesions. This finding validates the results of Maire et al. and Hayakawa et al. ${ }^{26,31}$ Studies investigating the relationship between preoperative pancreatic juice CEA levels and postoperative dysplasia grade of IPMNs found a significant correlation between high pancreatic juice CEA levels and HR-IPMNs. ${ }^{25,31,32}$ However, the main disadvantage of pancreatic juice studies is the risk of pancreatitis.

According to our data, cyst fluid CEA levels were significantly higher in LR-MCNs than in LR-IPMNs. Nagashio et al. ${ }^{23}$ defined cutoff levels for differentiating between MCNs and IPMNs for cyst fluid CEA and CA $125(67.3 \mathrm{ng} / \mathrm{mL}$ and $10.0 \mathrm{U} / \mathrm{mL}$, respectively) through ROC curve analysis in 18 IPMNs and 21 MCNs. However, they did not include the histopathologic type of the cysts in their cutoff analysis. In this study, we determined a cutoff level, $>100 \mathrm{ng} / \mathrm{mL}$, that could differentiate LR-IPMNs from LR-MCNs with a high AUROC $(0.93 ; 95 \%$ CI, $0.5-0.8)$ by considering the degree of dysplasia of the cysts.

The present study had several limitations. First, this was a single-center, retrospective, observational study that included a relatively small number of patients. Second, IPMNs were not further classified according to subtype but rather by the degree of dysplasia. As data on the histologic subtypes of the IPMNs were not available, the correlation between IPMN subtype, cyst fluid CEA level, and the risk of malignant transformation could not be determined. Third, as we did not have histopathologically verified HR-MCNs with prior cyst fluid CEA results, we were unable to compare the data for resected LRMCNs with those for HR-MCNs.

In conclusion, cyst fluid CEA measurement may be used as a complementary test not only for differentiating mucinous from nonmucinous PCLs, but also for differentiating LRIPMNs from LR-MCNs and HR-IPMNs. A cyst fluid CEA cutoff level of $>100 \mathrm{ng} / \mathrm{mL}$ had a $100 \%$ NPV for differentiating LR-IPMNs from LR-MCNs and HR-IPMNs.

Conflicts of Interest

The authors have no potential conflicts of interest.

Funding

None.

\section{Acknowledgments}

We thank our procedure nurses Deniz Akıncl, Ayșe Tezel and Aysel Salman for their dedication.

\footnotetext{
Author Contributions

Conceptualization: Ibrahim Hakkı Köker

Data curation: IHK, Nurcan Ünver, Fatma Ümit Malya, Elmas Biberci Keskin

Formal analysis: Ömer Uysal
}

Investigation: IHK, NÜ, FÜM

Methodology: ÖU

Project administration: Hakan Şentürk

Resources: HŞ

Software: ÖU

Supervision: NÜ, FÜM, HȘ

Validation: NÜ,FÜM, HŞ

Visualization: FÜM, EBK, HŞ

Writing-original draft: IHK

Writing-review\&editing: IHK, HŞ

\section{ORCID}

Ibrahim Hakkı Köker:

Nurcan Ünver:

Fatma Ümit Malya:

Ömer Uysal:

Elmas Biberci Keskin:

Hakan Șentürk: https://orcid.org/0000-0002-4513-6927 https://orcid.org/0000-0001-7392-6099 https://orcid.org/0000-0002-6593-6112 https://orcid.org/0000-0002-8833-697X https://orcid.org/0000-0002-5528-830X https://orcid.org/0000-0002-2440-4478

\section{REFERENCES}

1. Zerboni G, Signoretti M, Crippa S, Falconi M, Arcidiacono PG, Capurso G. Systematic review and meta-analysis: prevalence of incidentally detected pancreatic cystic lesions in asymptomatic individuals. Pancreatology 2019;19:2-9.

2. Basturk O, Coban I, Adsay NV. Pancreatic cysts: pathologic classification, differential diagnosis, and clinical implications. Arch Pathol Lab Med 2009;133:423-438.

3. van Huijgevoort NCM, Del Chiaro M, Wolfgang CL, van Hooft JE, Besselink MG. Diagnosis and management of pancreatic cystic neoplasms: current evidence and guidelines. Nat Rev Gastroenterol Hepatol 2019;16:676-689.

4. Sentürk H. Management of cystic diseases of the pancreas. Turk J Gastroenterol 2014;25:1-18.

5. Basturk O, Hong SM, Wood LD, et al. A revised classification system and recommendations from the Baltimore consensus meeting for neoplastic precursor lesions in the pancreas. Am J Surg Pathol 2015;39:17301741.

6. Adsay NV, Fukushima N, Furukawa T, et al. Intraductal neoplasms of the pancreas. In: Bosman FT, Carneiro F, Hruban RH, Theise ND, eds. WHO classification of tumours of the digestive system. 4th ed. Lyon: International Agency for Research on Cancer; 2010. p. 304-313.

7. Tanaka M, Chari S, Adsay V, et al. International consensus guidelines for management of intraductal papillary mucinous neoplasms and mucinous cystic neoplasms of the pancreas. Pancreatology 2006;6:17-32.

8. Tanaka M, Fernández-del Castillo $\mathrm{C}$, Adsay V, et al. International consensus guidelines 2012 for the management of IPMN and MCN of the pancreas. Pancreatology 2012;12:183-197.

9. Senturk H, Köker IH, Keskin EB, Ünver N, Ince AT, Basaranoglu M. Needle based confocal laser endomicroscopy examination of pancreatic cysts: single center real life results. Gastroenterology 2018;154(6 Suppl 1):S-528.

10. Basar O, Yuksel O, Yang DJ, et al. Feasibility and safety of microforceps biopsy in the diagnosis of pancreatic cysts. Gastrointest Endosc 2018;88:79-86.

11. Mittal C, Obuch JC, Hammad H, et al. Technical feasibility, diagnostic yield, and safety of microforceps biopsies during EUS evaluation of pancreatic cystic lesions (with video). Gastrointest Endosc 2018;87:12631269.

12. Oh SH, Lee JK, Lee KT, Lee KH, Woo YS, Noh DH. The combination of cyst fluid carcinoembryonic antigen, cytology and viscosity increases the diagnostic accuracy of mucinous pancreatic cysts. Gut Liver 
2017;11:283-289.

13. Tanaka M, Fernández-Del Castillo $C$, Kamisawa T, et al. Revisions of international consensus Fukuoka guidelines for the management of IPMN of the pancreas. Pancreatology 2017;17:738-753.

14. European Study Group on Cystic Tumours of the Pancreas. European evidence-based guidelines on pancreatic cystic neoplasms. Gut 2018;67:789-804.

15. Elta GH, Enestvedt BK, Sauer BG, Lennon AM. ACG clinical guideline: diagnosis and management of pancreatic cysts. Am J Gastroenterol 2018;113:464-479.

16. Brugge WR, Lewandrowski K, Lee-Lewandrowski E, et al. Diagnosis of pancreatic cystic neoplasms: a report of the cooperative pancreatic cyst study. Gastroenterology 2004;126:1330-1336.

17. van der Waaij LA, van Dullemen HM, Porte RJ. Cyst fluid analysis in the differential diagnosis of pancreatic cystic lesions: a pooled analysis. Gastrointest Endosc 2005;62:383-389.

18. Nagula S, Kennedy T, Schattner MA, et al. Evaluation of cyst fluid CEA analysis in the diagnosis of mucinous cysts of the pancreas. J Gastrointest Surg 2010;14:1997-2003.

19. Park WG, Mascarenhas R, Palaez-Luna M, et al. Diagnostic performance of cyst fluid carcinoembryonic antigen and amylase in histologically confirmed pancreatic cysts. Pancreas 2011;40:42-45.

20. Cizginer S, Turner BG, Bilge AR, Karaca C, Pitman MB, Brugge WR. Cyst fluid carcinoembryonic antigen is an accurate diagnostic marker of pancreatic mucinous cysts. Pancreas 2011;40:1024-1028.

21. Al-Rashdan A, Schmidt CM, Al-Haddad M, et al. Fluid analysis prior to surgical resection of suspected mucinous pancreatic cysts. A single centre experience. J Gastrointest Oncol 2011;2:208-214.

22. Ngamruengphong S, Bartel MJ, Raimondo M. Cyst carcinoembryonic antigen in differentiating pancreatic cysts: a meta-analysis. Dig Liver Dis 2013;45:920-926.

23. Nagashio Y, Hijioka S, Mizuno N, et al. Combination of cyst fluid CEA and CA 125 is an accurate diagnostic tool for differentiating mucinous cystic neoplasms from intraductal papillary mucinous neoplasms. Pan- creatology 2014;14:503-509.

24. Gaddam S, Ge PS, Keach JW, et al. Suboptimal accuracy of carcinoembryonic antigen in differentiation of mucinous and nonmucinous pancreatic cysts: results of a large multicenter study. Gastrointest Endosc 2015;82:1060-1069.

25. Kawai M, Uchiyama K, Tani M, et al. Clinicopathological features of malignant intraductal papillary mucinous tumors of the pancreas: the differential diagnosis from benign entities. Arch Surg 2004;139:188-192.

26. Maire F, Voitot H, Aubert A, et al. Intraductal papillary mucinous neoplasms of the pancreas: performance of pancreatic fluid analysis for positive diagnosis and the prediction of malignancy. Am J Gastroenterol 2008;103:2871-2877.

27. Oppong KW, Dawwas MF, Charnley RM, et al. EUS and EUS-FNA diagnosis of suspected pancreatic cystic neoplasms: is the sum of the parts greater than the CEA? Pancreatology 2015;15:531-537.

28. Correa-Gallego C, Warshaw AL, Fernandez-del Castillo C. Fluid CEA in IPMNs: a useful test or the flip of a coin? Am J Gastroenterol 2009;104:796-797.

29. Kucera S, Centeno BA, Springett G, et al. Cyst fluid carcinoembryonic antigen level is not predictive of invasive cancer in patients with intraductal papillary mucinous neoplasm of the pancreas. JOP 2012;13:409413.

30. Scourtas A, Dudley JC, Brugge WR, Kadayifci A, Mino-Kenudson M, Pitman MB. Preoperative characteristics and cytological features of 136 histologically confirmed pancreatic mucinous cystic neoplasms. Cancer Cytopathol 2017;125:169-177.

31. Hayakawa H, Fukasawa M, Sato T, et al. Carcinoembryonic antigen level in the pancreatic juice is effective in malignancy diagnosis and prediction of future malignant transformation of intraductal papillary mucinous neoplasm of the pancreas. J Gastroenterol 2019;54:1029-1037.

32. Hirono S, Kawai M, Okada KI, et al. Factors associated with invasive intraductal papillary mucinous carcinoma of the pancreas. JAMA Surg 2017;152:e165054. 